\title{
Research on Flexible Specialized Curriculum System of Traffic and Transportation Major
}

\author{
Ping HAN, Li-li MA*, Jia YAO \& Wei LU \\ College of Mechanical Engineering, Jiamusi University, 154007, Jiamusi, China \\ *Corresponding Author
}

\begin{abstract}
Due to various influential factors, professional directions and characteristics of traffic and transportation varies among universities. This paper, taking Jiamusi University for example, discussed the specialized curriculum system of traffic and transportation major in the context of large engineering. Considering talent training characteristics and employment tendency of traffic and transportation, flexible curriculum system that combines students' interests with employment orientations was developed in this paper to overcome limitations of current curriculum system.
\end{abstract}

KEYWORD: traffic and transportation; major; specialized curriculum; employment orientation

\section{CLASSIFICATION ANALYSIS OF TRAFFIC AND TRANSPORTATION MAJOR}

In 2012, the Ministry of Education issued the "Undergraduate Major Directory of Ordinary Higher School (2012)", in which disciplines were divided into 13 categories. Among them, engineering category includes 31 major classes, and traffic and transportation major class (code 0818) includes the majors as below: traffic and transportation, traffic engineering, marine technology, marine engineering, flight technology. Due to the influence of geographical position, history evolution, school orientation, faculty strength, teaching and research level, employment demand and other factors, the professional directions and characteristics of traffic and transportation varies among universities, according to which the universities setting up traffic and transportation major can be divided into three categories[1].

The first category is the universities that traffic and transportation major belongs to automobile college. Setting of traffic transportation major is based on automobile related majors and curriculum system focuses on automobile application and road transportation engineering. This kind of university usually belongs to 985 or 211 which oriented to good employment, such as Harbin Institute of Technology and Chang'an University. The main employment directions are automobile manufacturing industry, transportation organization and management in large and medium-sized enterprises, vehicle technology management, development and testing of transportation equipment.

The second category is the universities which traffic and transportation major with certain historical evolution has unique specialty. Such as Lanzhou University, its traffic and transportation major mainly orient to rail traffic. Beijing University of Aeronautics and Astronautics, oriented to collaborative transportation of air and ground. Dalian Maritime University cultivates talents of water transportation, port management, foreign trade and transportation. The second category has definite employment directions, most graduates can directly be delivered to contracted enterprises, so the employment status is satisfactory.

The third category is the universities in the context of large engineering, which specialty and employment direction of the traffic and transportation majors in this category is not particularly distinctive compared with the above two. Traffic and transportation majors are usually set up in engineering colleges, but feature with relatively "soft" professional. This kind of colleges and universities belongs to local authority, and the employment situation is grim.

Taking Jiamusi University for example, this paper discussed the specialized curriculum system of traffic and transportation major in the context of large engineering. 


\section{TALENT TRAINING CHARACTERISTICS AND EMPLOYMENT TENDENCY OF TRAFFIC AND TRANSPORTATION}

As other majors of engineering type, traffic and transportation should cultivate the talents who are with solid foundation of scientific theory, master related engineering principles, flexibly apply theory to practice and make further innovations. In addition, the field of traffic and transportation covers widely [2-3].

The employment statistics of 2007-2010 showed that the graduate went to wide employment fields. $49 \%$ graduates entered the manufacturing and sales field of automobile and spare parts. Transportation enterprises, transportation engineering construction enterprises and insurance companies (car insurance) accounted for $8 \%$. 5\% entered in local sectors of traffic management. Other employment fields included vocational and technical colleges, logistics enterprises, further study for graduate education, and other industries irrelevant to transportation, the proportions were $5 \%, 5 \%, 13 \%, 15 \%$ respectively. However, employment situation of 2011-2014 became grimmer, and employment direction tended to be more decentralized. Less graduates entered in manufacturing field of automobile and spare parts, and transportation engineering construction enterprises.

The main reason is that the oversupply of university graduates in recent years gave the employers more opportunities to employ more technical graduates such as automobile engineering, mechanical engineering, or civil engineering. For the recent four years, more graduate were engaged in passenger and freight transportation, vehicle insurance, sales of automobile and spare parts, and logistics industry. Why? Just solid foundation of engineering theory and management consciousness of traffic and transportation appeals to the enterprises.

In the light of the new situation of the employment demand, educators of traffic and transportation should provide reasonable curriculum system to narrow the gap between talent cultivation and future employment demand. Without complete talent training program and corresponding curriculum system, the training principle of thick foundation, wide specification is just a dumb slogan in order to respond to the Ministry of Education.

\section{PROBLEMS ANALYSIS OF THE SPECIALIZED CURRICULUM SYSTEM OF TRAFFIC AND TRANSPORTATION}

In the context of large engineering training mode, courses of traffic and transportation can be divided into theoretical courses and practice courses. The study of theoretical courses is divided into three stages: courses of general education, courses of basic discipline, and specialized courses.

Freshmen are not allotted to any major when they are enrolled in, and cross-major general courses are offered in the first three terms. According to individual willingness and previous overall performance, students are distributed to ideal major to further study specialized courses. Courses of general education amount to 49 credits, was $25 \%$ of the total credits. Courses of basic discipline include: higher mathematics, university physics, university physics experiment, engineering drawing, introduction of professional cognition, amounting to 27 credits, was $18 \%$ of the total credits. Specialized courses are divided into professional foundation courses, compulsory courses and optional courses, was $25 \%, 22 \%$ and $10 \%$ of the total credits respectively. Practice courses include all kinds of internships, course designs, graduation design (thesis), amounting to 44 weeks.

Seen from the above data, the current curriculum system focus on formation of basic science, in line with the training principle of thick foundation, wide specification, but there are some limitations in training practice and execution of specialized courses.

\subsection{The specialized course system is lack of systematicness and integrality}

Traffic and transportation has three professional directions: automobile application, transportation planning and management, logistics engineering. Course varies among the three professional directions. From the fourth term to the sixth term all the students have the same specialized basic courses and compulsory courses, aiming to strengthen the engineering base. Specialized compulsory courses include operations research, structure of automobile, traffic engineering, traffic management and control, which span the main courses of the three professional directions, aiming to achieve wide specialization. Division and selection of professional direction happens in the seventh term.

Although the curriculum emphasizes professional base and is benefit to explore and cultivate students' interests, the overwhelming cultivation of professional base neglects the connection and transition among courses, causing the specialized course system is lack of systematicness and integrality.

\subsection{The optional course system is lack of flexibility}

When individual professional direction is determined, students should choose 5 courses from the total 7 optional courses in the corresponding professional direction. This system gives students 
little choice free, making the optional courses become compulsory ones. Furthermore in order to emphasize the systematicness and integrality, ban to choose courses across professional directions is not appropriate.

The employment market is dynamic, and any professional direction only fuzzily matches to employment demand in a wide range. It is impossible that talent training corresponds precisely to the job requirements, while the flexible system of optional courses that permits courses option acrossprofessional directions, across-departments, even across-colleges can contribute to form personal knowledge system for the students who has definite job desires and interests without adding to input and cost of teaching resources. The flexible system can enhance students' interests in learning and professional identity, and alleviate employment pressure.

\section{REFORM ORIENTATION OF SPECIALIZED CURRICULUM SYSTEM OF TRAFFIC AND TRANSPORTATION}

\subsection{The time of professional direction division can be appropriately advanced to strengthen the systematicness of talent training}

In view of the above problems, this paper suggested that the time of professional direction division can be advanced to the end of fifth term. That means courses learning according professional direction begins at the sixth term. Of course, this change is not only ahead of time, but also needs corresponding revision of the total system of specialized courses. The essential principle of revision is that the main courses of the three directions are compulsory in the fifth term, by which enable students to form basic acquaintance with every professional direction. Then compulsory and optional courses are set up according to individual professional direction from the sixth to seventh term, by which enhance students' systematicness of knowledge structure.

\subsection{Flexible curriculum system that combines students' interests with employment orientations can be developed}

Although ahead of professional direction division's time can enhance students' systematicness of knowledge structure, it also restricts students' selfdevelopment. This paper suggested flexible curriculum system that permits courses option across-professional directions, across-departments, and across-colleges. The flexibility does not mean a random choice, but have its boundary.

As shown in Figure 1, considering the advices and recommendations of the professional teachers, education experts, and employment enterprises, focusing on current and future employment requirements of special jobs, frame of flexible course option is developed as a beneficial supplement of current curriculum system. The implement of the frame can not only increase the complexity and cost of teaching management, but also provide the students who have definite job desires and interests with personal cultivation mode.

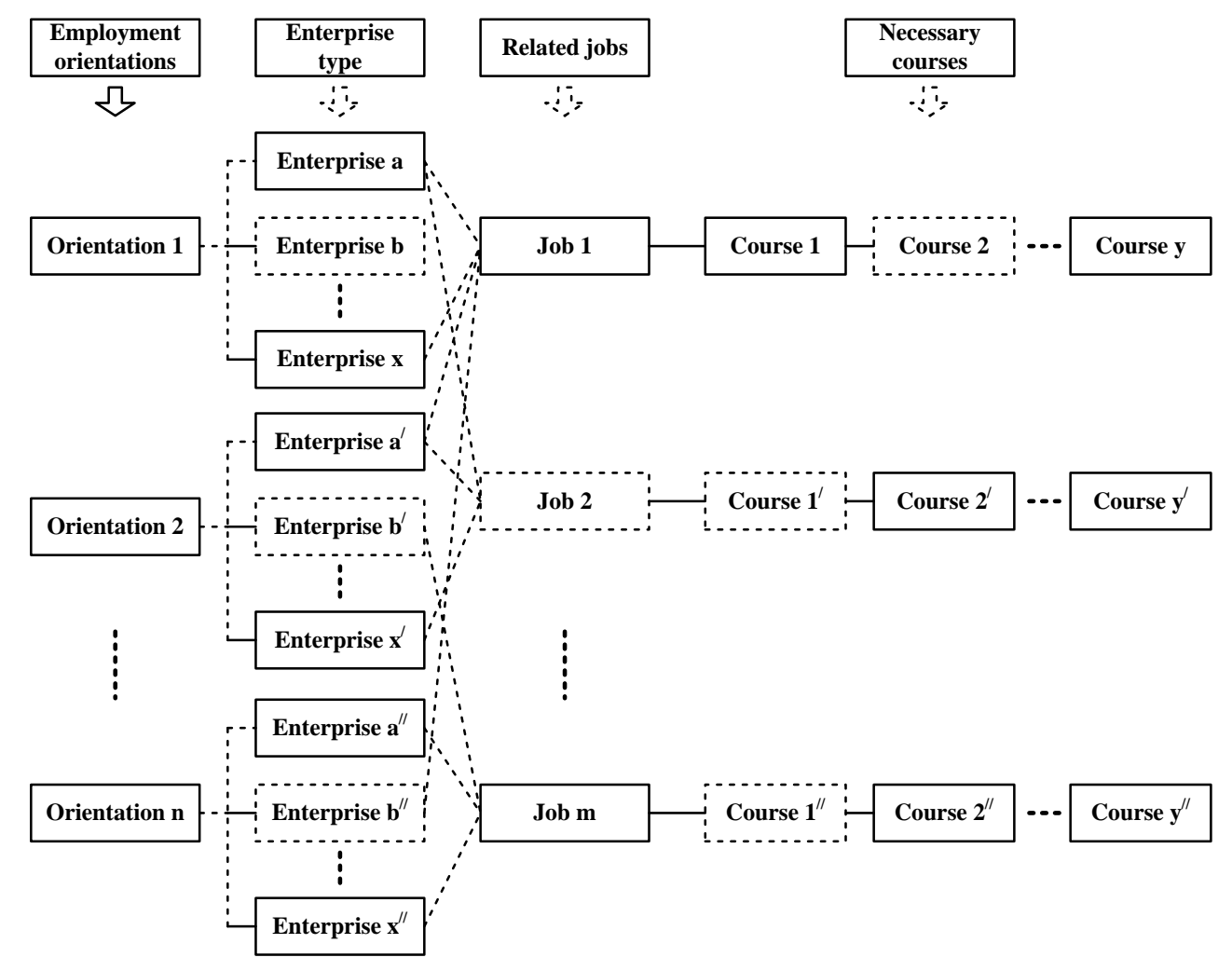

Figure 1. Frame of flexible curriculum system 


\section{CONCLUSIONS}

Reform orientation of specialized curriculum system is discussed above, whereas the reform of the practice links relevant to theory contents lies on cultivation mechanism and effective management other than systematic structure.

The practice in school factory, such as metalworking practice, automobile maintenance practice, should put more emphasis on students' actual participation and manipulative ability, and encourage innovations in the course of practice.

In the practice of course design, taking traffic management and control for example, students should be requested starting from solving the existing problems and complete the contents from traffic data collection, processing, status analysis, improvement and optimization to validation by simulation. This kind of course design can enhance the comprehensive application ability and innovative ability, because the theory related to the course of this design involves not only itself of traffic management and control, but also relevant knowledge covered in traffic survey, applied statistics of traffic and transportation, simulation of traffic engineering.

The practice link in the factory's plant should put emphasis on the breadth and depth of cooperation between school and enterprises. The ideal practice mode is to enable students to take part in the actual manufacturing and management activities as the internship, which can give students more opportunity to practice what they have learned.

\section{ACKNOWLEDGEMENT}

This project was supported by Jiamusi University educational science research project (JKB2012-006); Jiamusi university of science and technology innovation team building program (Cxtd-2013-01).

\section{REFERENCES}

[1] MA Si, PENG Qi-yuan, WANG Lin, ZHU Zhi guo. 2008. Research of Practical Teaching System Reform of Traffic and Transportation Major, Journal of Southwest Jiaotong Uiversity (Social Science), 9(6):95-99.

[2] PENG Qi-yuan, MA Si, WEN Chao. Reform and Practice in the Development of Talents for Traffic \& Transportation Industry, Journal of Southwest Jiaotong Uiversity (Social Science), 12(6):5-10.

[3] YANG Ya-zao, YANG Lin. 2014. Multilevel and modularized course system construction under "Plan for Educating and Training Outstanding Engineers"-Taking transportation specialty in Chongqing Jiaotong University for example. Research in Teaching, 37(1): 85-88. 